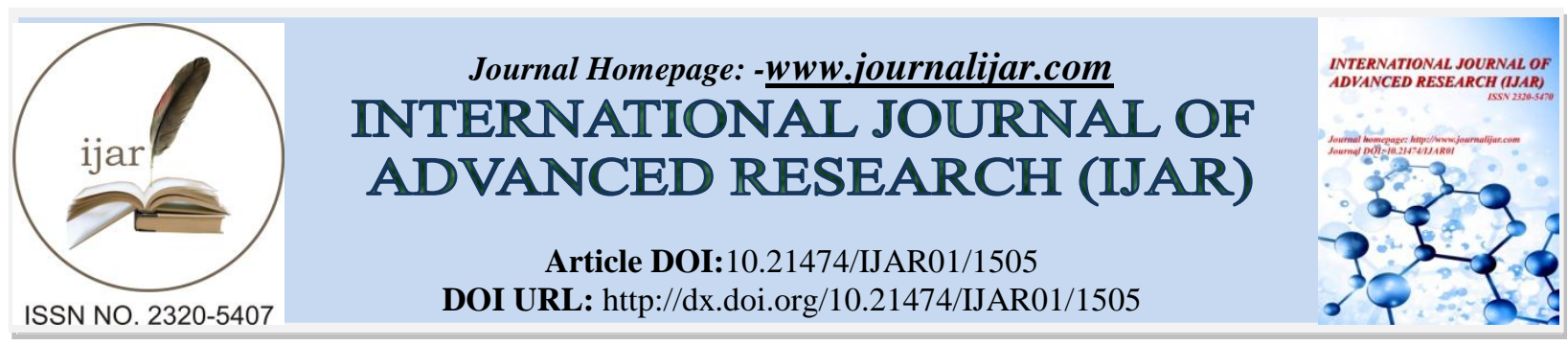

RESEARCH ARTICLE

\title{
GREEN COMPUTING
}

\section{Er. Kusum Sharma ${ }^{1}$ and Er Rajeev Sharma ${ }^{2}$.}

1. Computer Engineer at Himachal Pradesh Housing \& Urban Development Authority, Shimla (H.P.) India.

2. Joint Director, Department of Information Technology (H.P.) India .

\section{Manuscript Info}

\section{Manuscript History}

Received: 16 July 2016

Final Accepted: 19 August 2016

Published: September 2016

Key words:-

e-wastage, carbon foot prints,

Peripherals, green computing.
Abstract

Today Computers are widely used throughout the globe. The amount of usage of computer systems in the world also require heavy amount of electricity and leaves carbon foot prints. Also disposal of ewastage has become a problem. It is necessary to think about the environmental issues concerned with using computers because it is not possible to decrease the usage of computers. Need for green computing has arise.Green computing is the study of disposing, recycling and manufacturing of computers and peripheral devices in such a way which reduces its environmental effect and promote biodegradability or recyclability of out-dated products and factory waste. Green computing is important for all classes of systems, ranging from handheld systems to large-scale data centers.

Copy Right, IJAR, 2016,. All rights reserved.

\section{Introduction:-}

Green computing includes the implementation of best practices, such as energy efficiency and use of computers in eco friendly ways. In addition green technology aims to reduce resource consumption and improve the disposal of electronic waste (e-waste).

Reducing carbon footprints and taming energy efficiency is no longer just an option. It is now an inevitable future of the 21 st century business landscape.

A major point of research is searching and applying alternative nonhazardous materials in the product's manufacturing process. The idea of green computing is responsible use of computers and any other technologyrelated resources with minimal or no impact on the environment.

\section{Need for Green Computing:-}

Green computing can be helpful in reducing energy consumption and hence cost efficient system.

With cut in energy consumption reduction in carbon foot prints.

To make Disposal of e-waste in such a way which reduces environmental effects and hazards to human life.

Corresponding Author:-Er.Kusum Sharma.

Address:-Computer Engineer at Himachal Pradesh Housing \& Urban Development Authority, Shimla (H.P.) India. 


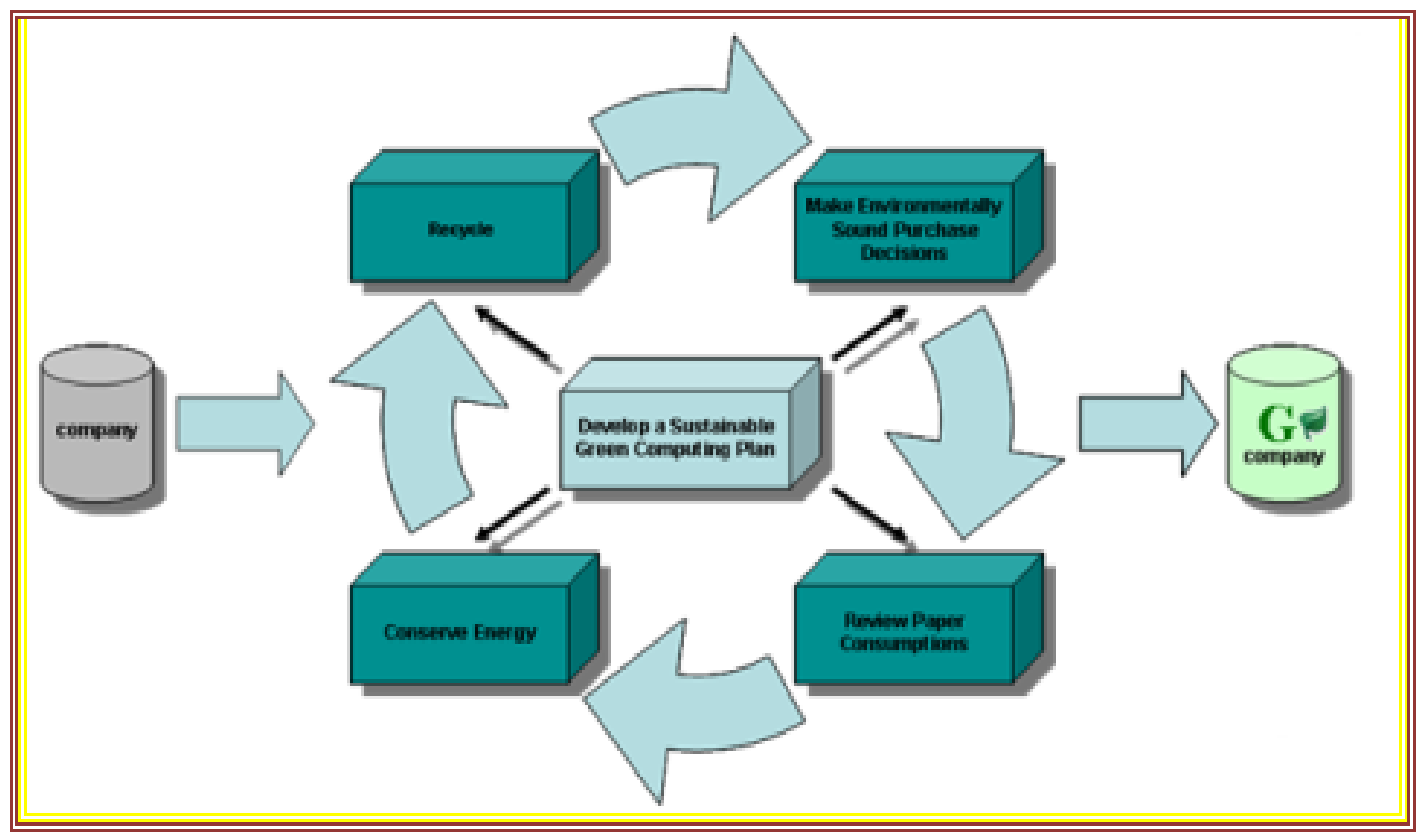

(Fig 1: Green Computing migration framework)

Small Tricks to follow green computing:-

- Use the hibernate or sleep mode when away from a computer for extended periods.

- Use flat-screen or LCD monitors, instead of conventional cathode ray tube (CRT) monitors

- Buy energy efficient notebook computers, instead of desktop computers

- Activate the power management features for controlling energy consumption

- Make proper arrangements for safe electronic waste disposal

- Turn off computers at the end of each day

- Refill printer cartridges, rather than buying new ones

- Instead of purchasing a new computer, try refurbishing an existing device.

Methods:-

Green computing practices include the development of environmentally sustainable production practices, energy efficient computers and improved disposal and recyclingprocedures.

To promote green computing concepts at all possible levels, the following four complementary approaches are employed:

- Green use: Minimizing the electricity consumption of computers and their peripheral devices and using them in an eco-friendly manner.[4]

- Green disposal: Re-purposing an existing computer or appropriately disposing of, or recycling, unwanted electronic equipment.[4]

- Green design: Designing energy-efficient computers, servers, printers, projectors and other digital devices.

- Green manufacturing: Minimizing waste during the manufacturing of computers and other subsystems to reduce the environmental impact of these activitiesGovernment regulatory authorities also actively work to promote green computing concepts by introducing several voluntary programs and regulations for their enforcement.[4]

Green computing for Data Centres:-

IT industry is using both time and money to find out the efficient use of energy and use technologies that reduce the total power consumption of servers and lower the heat generated. 
Eco-friendly data center designs use a synthetic white rubber roof, paint, and carpet that contain a low volatile organic compound (VOC), countertops made of recycled products, and energy-efficient mechanical and electrical systems at optimal efficiency.[5]

Virtualization is a major strategy to reduce data center power consumption. In virtualization, one physical server hosts multiple virtual servers. Virtualization enables data centers to strengthen their physical server infrastructure by hosting multiple virtual servers on a smaller number of more powerful servers, using less electricity and simplifying the data center. Besides getting much better hardware usage, virtualization reduces data center floor space, makes better use of computing power, and greatly reduces the data center's energy demands. [5]

In order to tackle the issue of data centers' huge power consumption, leading IT enterprises formed a non-profit group called the Green Grid in February 2007. This group has the responsibility to define and propagate the best energy-efficient practices in data center operation, construction and design and technology standards.

\section{World towards Green computing:-}

Faced with the stark realities of global warming and rising energy costs, government agencies and private firms worldwide are examining ways to protect the environment. To address what is increasingly being perceived as a crisis, there is a growing global movement to implement more environmentally friendly computing "Green computing" is the name attached to this movement, which represents an environmentally responsible way to reduce power and environmental waste. Toward this goal, the U.S. Environmental Protection Agency's Energy Star program has developed compliance requirements for computer equipment. The U.S. House of Representatives Resolution 5646, passed in July 2006, calls for the EPA’s Energy Star program to research: [10]

- The amount of power consumed by corporate and federal data centers .

- Industry measures to develop energy-efficient servers .

- Possible incentives to convince businesses to use energy-saving technologies.

In Europe, government agencies have set up a number of environmental regulations addressing waste management, recycling, disposal of certain types of waste, industrialemissions and pollution control. The European Union is also setting up a system that encourages business to voluntarily develop their own environmental standards and practices.[10]

\section{Conclusion:-}

Green computing refers to a responsible way to address the issue of global warming. Green computing best practices and policies should cover power usage, reduction of paper consumption, as well as recommendations for new equipment and recycling old machines. Organizational policies should include communication and implementation. The effective implementation for optimizing usage of computer systems can be achieved only if all the organizations, hardware manufacturers, employees, students and all the people in the world using computers are aware about green computing.Point of researchis searching and applying alternative technology with minimal or no impact on the environment.

\section{References:-}

1. http://en.wikipedia.org/wiki/Green_computing

2. www.computer weekly.com

3. www.Techtargetnetwork.com

4. www.techopedia.com

5. BiswajitSaha,Green Computing, 2014.

6. Mr.N.P.Jadhav,Mr.R.S.Kamble,Mr.S.V.Kamble, Green Computing-New Approaches of Energy Conservation and E- Waste Minimization

7. SwastiSaxena,Green Computing: Need of the Hour, Feb 2015

8. VimalP.Parmar, Apurva K. Pandya, Dr. CK Kumbharana, Optimization of Energy Usage for Computer Systems by Effective Implementation of Green Computing.

9. www.slideshare.net

10. http://h20426.www2.hp.com/program/carepack/pdf/5steps.pdf 